\title{
Emprego de água biossalina na germinação de sementes de espécies florestais da
}

\section{Caatinga - uma revisão}

\author{
Use of biosaline water in the germination of seeds of Caatinga forest species - a review \\ Uso de agua biosalina en la germinación de semillas de especies forestales de Caatinga - una \\ revisión
}

Recebido: 13/08/2021 | Revisado: 22/08/2021 | Aceito: 23/08/2021 | Publicado: 24/08/2021

\author{
Agda Raiany Mota dos Santos \\ ORCID: https://orcid.org/0000-0002-9485-2786 \\ Universidade Federal Rural de Pernambuco, Brasil \\ E-mail: agdaraiany8@gmail.com \\ Monalisa Alves Diniz da Silva \\ ORCID: https://orcid.org/0000-0001-9052-7380 \\ Universidade Federal Rural de Pernambuco, Brasil \\ E-mail: monalisa.diniz@ufrpe.br \\ Lady Daiane Costa de Sousa \\ ORCID: https://orcid.org/0000-0002-0942-4673 \\ Universidade Federal Rural de Pernambuco, Brasil \\ E-mail: teodosiod01@gmail.com \\ Ariana Veras de Araújo \\ ORCID: https://orcid.org/0000-0002-4869-7834 \\ Universidade Federal do Ceará, Brasil \\ E-mail: ariana.veras@hotmail.com \\ Edilma Pereira Gonçalves \\ ORCID: https://orcid.org/0000-0001-5150-7088 \\ Universidade Federal do Agreste de Pernambuco, Brasil \\ E-mail: edilmapg@hotmail.com
}

\begin{abstract}
Resumo
Com a redução das águas de boa qualidade e o aumento de águas biossalinas no mundo tornam-se necessários estudos voltados para a produção de mudas de espécies florestais, visto que há uma necessidade de recuperação de áreas degradadas e estas podem estar sujeitas a diversos estresses, sobretudo o salino. A presente revisão de literatura possui como objetivo avaliar artigos científicos sobre o emprego de águas biossalinas na germinação de sementes de espécies florestais da Caatinga, assim como averiguar as temáticas abordadas (salinidade, estresse salino, águas biossalinas, efeito dos sais na germinação de sementes, tolerância à salinidade, estratégias para uso de águas biossalinas, produção de mudas com águas biossalinas, sementes florestais submetidas à salinidade) nas publicações, idiomas adotados (português, inglês e espanhol) e o número de artigos por base de dados. Com as temáticas utilizadas abordadas foi possível encontrar um número muito elevado de artigos nas bases de dados (Scielo, Web of Science, Periódico Capes e Google Acadêmico) durante os 20 anos analisados, totalizando 217.477, entretanto com maior aprofundamento das temáticas para espécies florestais da Caatinga esse número reduziu drasticamente chegando a 183 artigos, com maior predominância na base de dados Google Acadêmico. Os resultados sugerem que são necessárias mais pesquisas com relação ao estresse salino, ao qual as espécies florestais da Caatinga estão sujeitas, pois a salinidade é uma realidade nesta floresta tropical seca.
\end{abstract}

Palavras-chave: Salinidade; Processo germinativo; Estabelecimento inicial de plântulas.

\begin{abstract}
With the reduction of good quality water and the increase of biosaline water in the world, studies on the production of seedlings of forest species are necessary, since there is a need for recovery of degraded areas and these may be subject to various stresses, especially saline. The present literature review aims to evaluate scientific articles about the use of biosaline water in the germination of seeds of Caatinga forest species, as well as to investigate the themes addressed (salinity, salt stress, biosaline water, salts on seed germination, salinity tolerance, strategies for use of biosaline waters, seedling production with biosaline waters, forest seeds subjected to salinity) in the publications, languages adopted (Portuguese, English and Spanish) and the number of articles per database. With the themes used, it was possible to find a very high number of articles in the databases (Scielo, Web of Science, Periódico Capes and Google Scholar) during the 20 years analyzed, totaling 217,477. However, with more in-depth study of the themes for Caatinga forest species, this number was drastically reduced, reaching 183 articles, with a greater predominance in the
\end{abstract}


Google Scholar database. The results suggest that more research is needed regarding the saline stress to which Caatinga forest species are subjected, since salinity is a reality in this dry tropical forest.

Keywords: Salinity; Germination process; Initial seedling establishment.

\begin{abstract}
Resumen
Con la reducción de las aguas de buena calidad y el aumento de las aguas biosalinas en el mundo, se hacen necesarios los estudios sobre la producción de plántulas de especies forestales, ya que es necesario recuperar las zonas degradadas y éstas pueden estar sometidas a diversos estreses, especialmente salinos. La presente revisión bibliográfica tiene como objetivo evaluar artículos científicos sobre el empleo de agua biosalina en la germinación de semillas de especies forestales de Caatinga, así como investigar los temas abordados (salinidad, estrés salino, agua biosalina, efecto de las sales en la germinación de las semillas, tolerancia a la salinidad, estrategias de uso de las aguas biosalinas, producción de plántulas con aguas biosalinas, semillas forestales sometidas a la salinidad) en las publicaciones, idiomas adoptados (portugués, inglés y español) y número de artículos por base de datos. Con los temas abordados fue posible encontrar un número muy elevado de artículos en las bases de datos (Scielo, Web of Science, Periódico Capes y Google Acadêmico) durante los 20 años analizados, totalizando 217.477, sin embargo con la mayor profundización de los temas para las especies forestales de Caatinga este número se redujo drásticamente llegando a 183 artículos, con mayor predominio en la base de datos de Google Acadêmico. Los resultados sugieren que es necesario investigar más sobre el estrés salino al que están sometidas las especies del bosque de Caatinga, ya que la salinidad es una realidad en este bosque seco tropical.
\end{abstract}

Palabras clave: Salinidad; Proceso de germinación; Establecimiento inicial de plántulas.

\title{
1. Introdução
}

Atualmente a água, fonte primordial para a existência de vida no planeta, vem sendo o motivo de muitas preocupações, já que tanto sua quantidade como qualidade estão comprometidas, impactando diretamente a qualidade de vida das pessoas, das plantas, dos animais e comprometendo o desenvolvimento econômico de diversas regiões do mundo, uma vez que a água desempenha papel crucial em todo organismo vivo como respiração, digestão e a reprodução (Carvalho et al., 2020).

Um dos problemas que mais reduz a qualidade da água é o excesso de sais presentes, tanto nas águas superficiais como subterrâneas, sendo recorrente, sobretudo, em regiões áridas e semiáridas em virtude das irregularidades das chuvas e da elevada taxa de evapotranspiração e, nessa ocasião verifica-se o acúmulo de sais tanto nas águas como também no solo em quantidades desvantajosas ao desenvolvimento das plantas (Nogueira et al., 2012). Vale ressaltar que a salinidade pode suceder-se também pela condução inadequada do solo e da água em áreas agrícolas, como por exemplo, a drenagem insuficiente e o uso incorreto de fertilizantes (Dantas et al., 2019).

Paralelamente aos problemas de salinidade nas águas e no solo, existem os inconvenientes advindos do desmatamento, ocasionados principalmente pelo desordenado crescimento da agricultura e pela exploração inadequada dos recursos florestais, como exemplo a madeira. É o caso do domínio vegetal Caatinga, floresta tropical seca, que vem sofrendo ao longo dos anos diversas intervenções humanas e com isso a vegetação típica do Semiárido se encontra com menos de 50\% de sua cobertura original (Dantas et al., 2019).

Com isso torna-se necessário a produção de mudas das espécies florestais para fins de recuperação desses ambientes degradados, contudo, especialmente na região onde se situa a Caatinga há uma limitação quanto aos recursos hídricos disponíveis para fornecimento à germinação de sementes e desenvolvimento de plântulas, sendo muito utilizadas as fontes subterrâneas e estas dispõem de elevados teores salinos que podem comprometer o processo germinativo de espécies sensíveis a tal fator (Ramos et al., 2018). Portanto, é imprescindível verificar o comportamento das espécies com potencial de revegetação em níveis variados de salinidade, para indicar as mais promissoras.

Geralmente cada espécie responde de uma maneira diferente a presença de sais, todavia a capacidade de suportarem os sais ocorre quando estas utilizam mecanismos seletivos e evitam que excessivas quantidades entrem nas suas células e 
provoquem efeitos tóxicos e osmóticos. (Nogueira et al., 2012). Em virtude dos seus fatores adaptativos como as raízes profundas e folhas modificadas, as espécies florestais da Caatinga são tolerantes aos sais (Santos et al., 2020).

Na ocasião de haver altos níveis salinos no solo ou na água, o potencial osmótico é comprometido, reduzindo-se a absorção de água tanto pela semente em processo de germinação como também pela planta e, no caso específico da germinação pode retardar ou até inibir totalmente o processo. Além do mais, os sais podem provocar toxicidade na semente, levando a morte do embrião (Santos et al., 2020).

Dessa forma, é essencial que a água empregada na germinação seja de boa qualidade e na quantidade adequada, pois esta é a responsável pela retomada das atividades metabólicas como a digestão e mobilização das reservas, resultando no desenvolvimento do eixo embrionário, culminando com a protrusão da raiz primária, e posterior estabelecimento da plântula (Taiz et al., 2017). Além disso, os sais podem causar alterações fisiológicas e bioquímicas adversas nas sementes em germinação, dificultando o posterior estabelecimento de mudas, uma vez que estas serão expostas as condições de estresses bióticos e abióticos (Taiz et al., 2017).

Sabe-se que a água de boa qualidade para produção de mudas é escassa e que há uma grande necessidade de incrementar as pesquisas quanto à produção de mudas de espécies florestais com águas biossalinas para fins de recuperação de áreas degradadas, sobretudo em ambientes salinizados. Além disso, a aplicação dessas águas para produzir mudas é bastante viável aos programas de reflorestamento, pois estas possuem menores custos e em muitas ocasiões ou épocas no ano são as únicas disponíveis.

Assim o objetivo da pesquisa foi avaliar as publicações na forma de artigos científicos sobre o emprego de águas biossalinas na germinação de sementes de espécies florestais da Caatinga, assim como também averiguar as temáticas abordadas nas publicações, idiomas adotados e o número de artigo por base de dados.

\section{Metodologia}

Uma revisão bibliográfica ou revisão de literatura é um diagnostico critico, sistemático e vasto de publicações acerca de uma área do conhecimento definida, que busca elucidar e debater um determinado tema com base em referências teóricas publicadas em livros, revistas, periódicos. Ressalta-se que a pesquisa bibliográfica não é somente uma réplica do que foi mencionado anteriormente e sim uma análise do um tema sob uma nova perspectiva com conclusões contemporâneas (Martins, 2001).

Foram utilizados para compor a base de dados artigos científicos com as seguintes temáticas: salinidade, estresse salino, águas biossalinas, tolerância à salinidade, estratégias para uso de águas biossalinas, produção de mudas com uso de água biossalina, efeito dos sais na germinação de sementes, sementes florestais submetidas à salinidade. Optou-se como procedimento-metodológico a revisão bibliográfica do tipo narrativa, onde é possível o acesso às experiências de autores que já pesquisaram sobre o assunto.

O levantamento de dados compreendeu um período entre 2000 a 2020, totalizando 20 anos, com três idiomas (Português, Inglês e Espanhol). Utilizou-se as bases de dados Scielo, Periódicos Capes, Web of Science e Google Acadêmico. Após a coleta dos dados foi realizada a leitura dos materiais e as principais informações colhidas foram estruturadas quando ao ano de publicação, idioma, base de dados da publicação, sendo os temas abordados confeccionados na forma de gráficos; seguindo-se com as discussões quanto aos resultados.

\section{Resultados}

Utilizando as palavras-chave e expressões descritas na metodologia foram encontrados no período de 2000 a 2020 , 217.477 artigos publicados nas plataformas Web of Science, Scielo, Periódicos Capes e Google Acadêmico. Sendo que destes 
artigos 142.920 foram publicados na base de dados Google Acadêmico, 72.122 Web of Science, 1775 Scielo e 660 Periódicos Capes (Figuras 1A e B.

A plataforma Google Acadêmico possui uma maior acessibilidade e, portanto, dispõe de um maior número de artigos no seu acervo, por isso é uma base bem eficiente. O Web of Science é uma plataforma que exige que o interessado seja registrado para dispor do acesso aos periódicos, sendo que esse registro pode ser feito com um e-mail pessoal e senha ou por meio do vínculo institucional de uma universidade.

O Scielo é uma plataforma que publica trabalhos das mais diversas temáticas com acesso gratuito a todo o público. Seus trabalhos são publicados em três idiomas inglês, português e espanhol. A base de dados, Periódicos Capes é bastante acessada, entretanto nas temáticas sobre o emprego de água biossalina na germinação de sementes de espécies florestais, o número de artigos foi bastante reduzido, em relação às demais bases de dados.

A base de dados Web of Science apresentou uma tendência crescente no número de artigos ao longo dos anos com as temáticas abordadas no levantamento bibliográfico, o que indica a relevância do tema e o quanto às pesquisas estão crescendo. Já o Google Acadêmico apresentou a mesma tendência até o ano de 2017, entretanto houve um declínio no número de publicações nos anos de 2018, 2019 e 2020 (Figura 1A).

Com relação as bases de dados Periódicos Capes e o Scielo observou-se uma oscilação ao longo dos anos. O ano com mais artigos publicados na base de dados Periódicos Capes foi 2011 com 64 artigos, já a base de dados Scielo publicou mais artigos (168) em 2018 (Figura 1B). 
Figura 1 - Número de publicações com as palavras-chave e expressões (salinidade, estresse salino, águas biossalinas, efeito dos sais na germinação de sementes, tolerância à salinidade, estratégias para uso de águas biossalinas, produção de mudas com águas biossalinas, sementes florestais submetidas à salinidade) sobre o uso de águas biossalinas no processo de germinação de sementes de espécies florestais, nas bases de dados Web of Science e Google Acadêmico (A) e Scielo e Periódicos Capes (B), durante o período de 2000 a 2020.
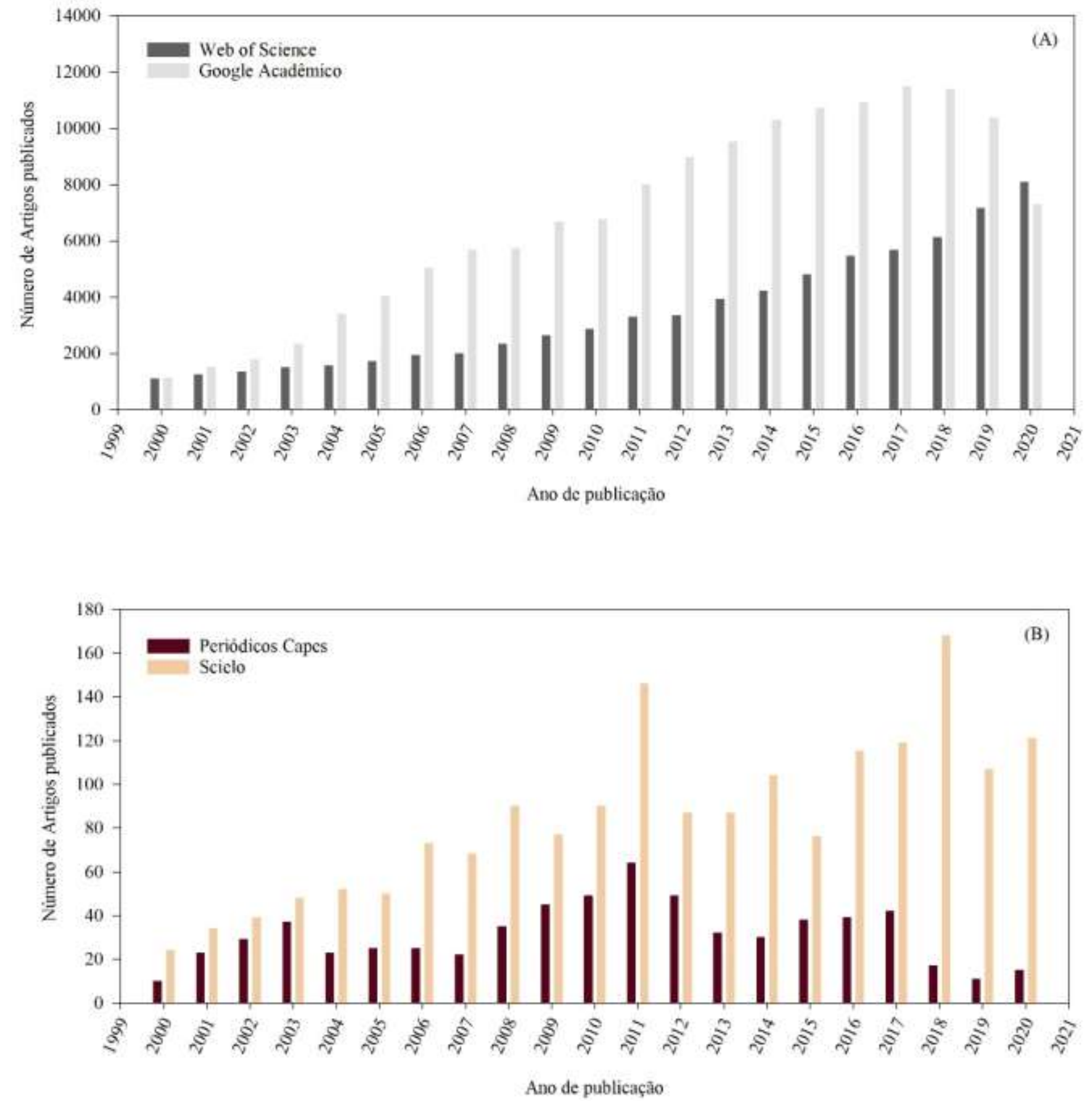

Fonte: Autores (2021).

Ao especificar a pesquisa por meio das palavras-chave e expressões para espécies florestais da Caatinga, o número declina consideravelmente nas bases de dados Scielo, Web of Science e Periódicos Capes, evidenciando que nos acervos dessas bases de dados existe uma escassez da temática (Figura 2). Quanto à base de dados Google Acadêmico por possuir uma maior abrangência e uma menor especificidade no seu acervo, possui um número maior de artigos voltados às espécies 
florestais da Caatinga (Figura 2). Totalizando nas quatro bases de dados 183 artigos no período de 2000 a 2020 , sendo que nos anos de 2000 a 2005 e 2012 não foi possível encontrar publicações com essa temática.

Figura 2 - Número de publicações com as palavras-chave e expressões: salinidade de espécies florestais da Caatinga, estresse salino em espécies florestais da Caatinga, uso de águas biossalinas em espécies florestais da Caatinga, efeito dos sais na germinação de sementes de florestais da Caatinga, tolerância à salinidade de espécies florestais, estratégias para uso de águas biossalinas em espécies florestais da Caatinga, produção de mudas de espécies florestais da Caatinga com águas biossalinas e sementes florestais da Caatinga submetidas à salinidade, sobre o uso de águas biossalinas no processo de germinação de sementes de espécies florestais da Caatinga, nas bases de dados Scielo, Web of Science, Periódicos Capes e Google Acadêmico, durante o período de 2000 a 2020.

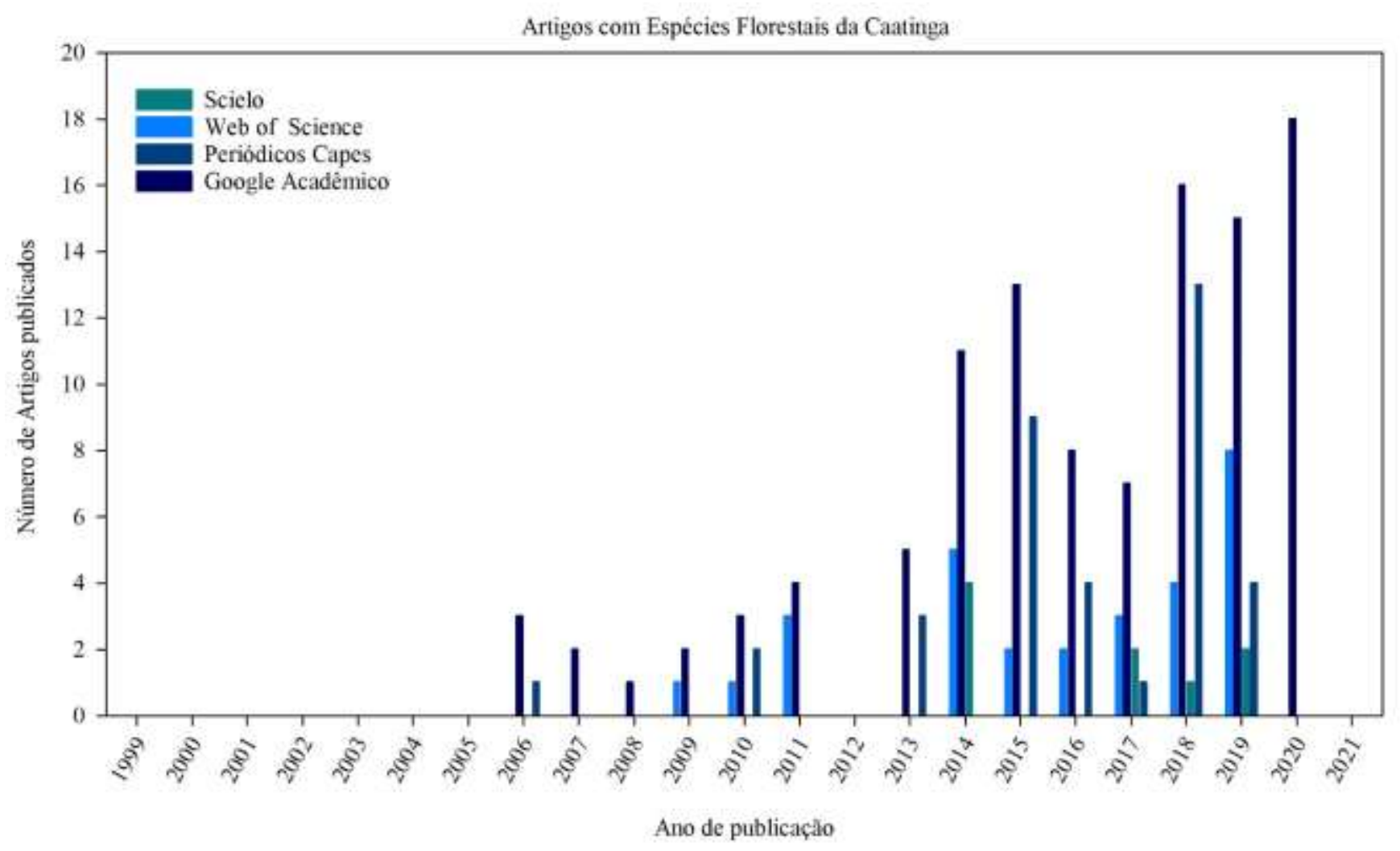

Fonte: Autores (2021).

Em relação às palavras-chave e expressões utilizadas para a busca dos artigos relacionadas ao emprego de águas biossalinas na germinação de sementes de espécies florestais da Caatinga, foi possível observar que palavras ou expressões menos específicas como salinidade, estresse salino e tolerância à salinidade, foram encontradas em uma maior quantidade de artigos publicados principalmente nas bases de dados Web of Science e Google Acadêmico, enquanto que Scielo e Periódicos Capes apresentaram uma quantidade pouco expressiva de artigos (Figuras 3 A, B e D).

Destaca-se que a expressão "águas biossalinas" possui um número bem reduzido de artigos na base de dados Scielo, apresentando apenas cinco artigos ao longo dos anos. Já as plataformas Web of Science e Google Acadêmico apresentaram um número considerável de artigos, entretanto a base de dados Periódicos Capes não apresentou nenhum resultado, isso evidencia que essa temática é pouco discutida ou estudada nos trabalhos científicos dessa base de dados (Figura 3 C). 
Figura 3 - Número de artigos publicados com as palavras-chave: Salinidade (A), Estresse salino (B), Águas biossalinas (C) e Tolerância à salinidade (D), nas bases de dados Web of Science, Scielo, Google Acadêmico e Periódicos Capes, durante o período de 2000 a 2020.
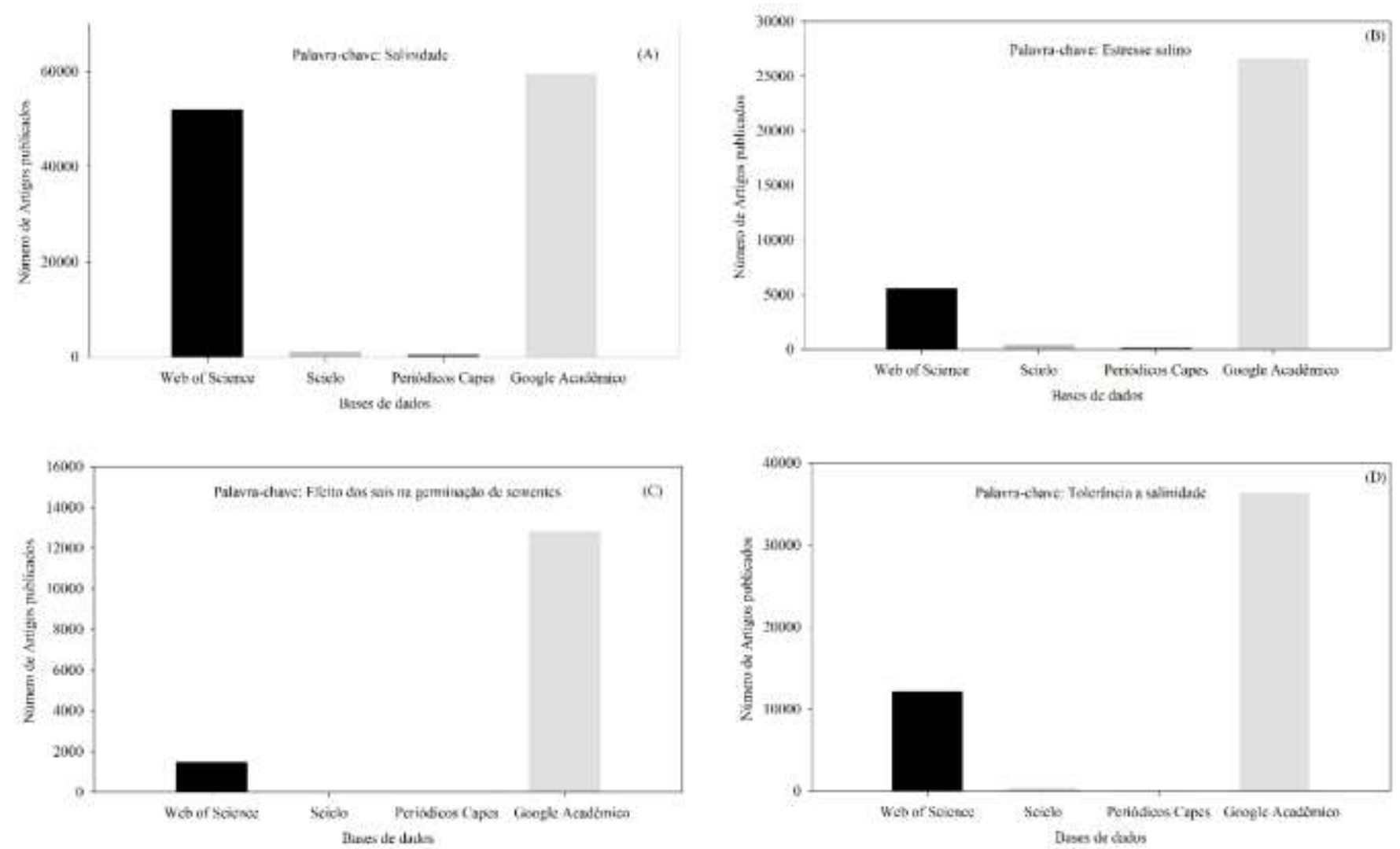

Fonte: Autores (2021).

A expressão "estratégias para uso de águas biossalinas”, apresentou um número considerável de artigos nas bases de dados Google Acadêmico e Scielo, entretanto reduziu-se para apenas quatro no Web of Science e no Periódicos Capes não apresentou nenhum resultado (Figura 3A). A expressão "produção de mudas com uso de águas biossalina" mostrou a mesma tendência da expressão anterior, com maior número de artigos no Google Acadêmico e Scielo, sendo que na plataforma Web of Science registrou-se apenas três e nenhum artigo foi verificado no Periódicos Capes (Figura 3B).

Em relação à expressão "efeito dos sais na germinação de sementes", esta apresentou um número de artigos bastante expressivo, sobretudo no Google Acadêmico com 12794 artigos e em segundo lugar a plataforma Web of Science com 1482, já o Scielo e Periódicos Capes não apresentaram resultados para esta expressão (Figura 3C). Quanto à expressão "sementes florestais submetidas à salinidade" só foi possível encontrar artigos no Google Acadêmico, enquanto que nas bases de dados Web of Science, Scielo e Periódicos Capes não foram encontrados artigos (Figura 3D). 
Figura 4 - Número de artigos publicados com as expressões: Estratégias para uso de águas biossalinas (A), Produção de mudas com uso de água biossalina (B), Efeito dos sais na germinação de sementes (C) e Sementes florestais submetidas à salinidade (D), nas bases de dados Web of Science, Scielo, Google Acadêmico e Periódicos Capes, durante o período de 2000 a 2020.
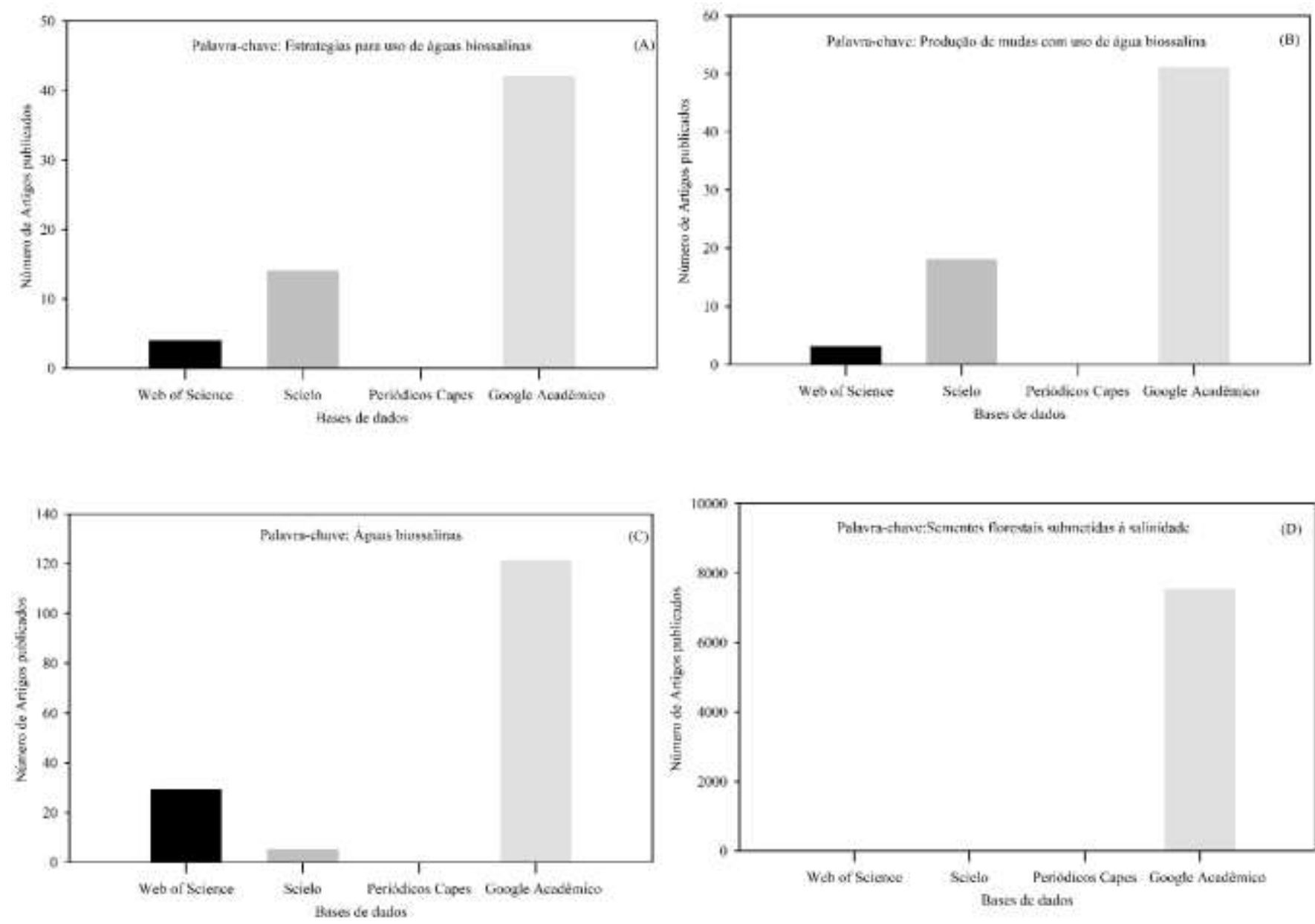

Fonte: Autores (2021).

Do total de artigos publicados há uma predominância do idioma inglês, com uma frequência de 93\%, seguido pelo português com $5 \%$ e o espanhol com apenas $2 \%$ (Figura 5). 
Figura 5 - Porcentagem de artigos publicados, quanto ao idioma com as palavras-chave e expressões (salinidade, estresse salino, águas biossalinas, efeito dos sais na germinação de sementes, tolerância à salinidade, estratégias para uso de águas biossalinas, produção de mudas com águas biossalinas, sementes florestais submetidas à salinidade) sobre o uso de águas biossalinas no processo de germinação de sementes de espécies florestais, nas bases de dados Web of Science e Google Acadêmico e Scielo e Periódicos Capes, durante o período de 2000 a 2020.

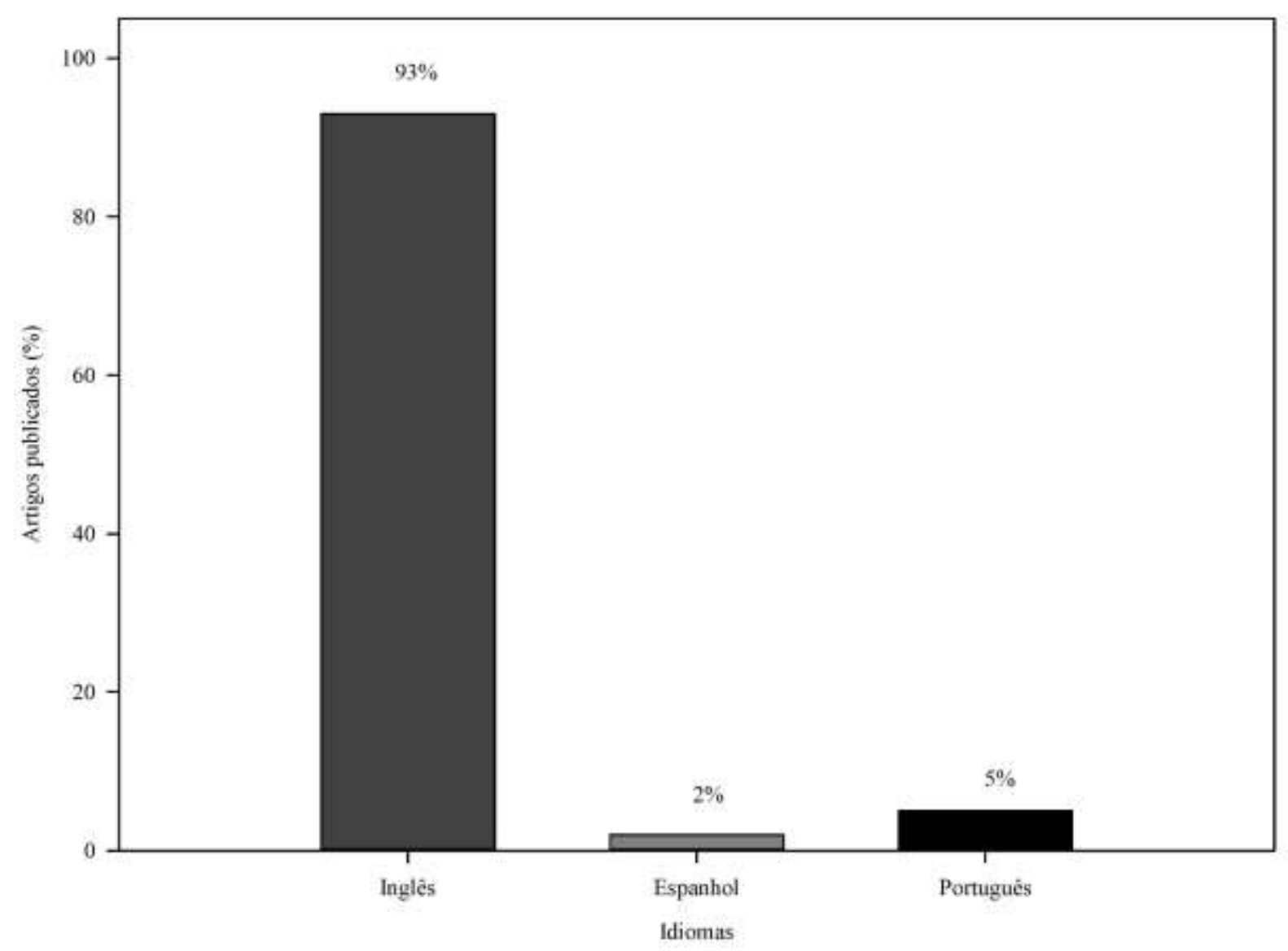

Fonte: Autores (2021).

\section{Discussões}

Em geral, o número de artigos sobre o uso de águas biossalinas no processo de germinação de sementes de espécies florestais da Caatinga é consideravelmente baixo (Figura 2). Isto evidencia a carência de estudos sobre o manejo e análise de sementes florestais da Caatinga nas diversas situações de estresse salino e como o mesmo influencia no processo germinativo (Lima, Oliveira, \& Meiado, 2020). Além disso, na Caatinga, floresta tropical seca, estão presentes além da salinidade, o déficit hídrico, a elevada intensidade luminosa, as altas temperaturas, as baixas precipitações e umidade relativa do ar, associadas à elevada taxa de evaporação; sendo que em conjunto tais condições contribuem para um ambiente altamente estressante para as sementes e estabelecimento inicial das plântulas (Tavares Filho et al., 2010).

Sendo assim é necessário verificar como esses estresses associados influenciam a germinação das sementes, já que o estudo isolado não condiz com as condições presentes no ambiente em que elas se encontram (Gonçalves et al., 2020).

Dessa forma, conhecendo todo o potencial que as espécies florestais presentes na Caatinga podem oferecer, são necessários estudos para a efetivação da recuperação das áreas degradadas e salinizadas com espécies nativas adaptadas a tais condições (Santos et al., 2020). 
Nas temáticas abordadas foi possível observar que existe um avanço nos estudos sobre o comportamento de espécies nativas da Caatinga submetidas a águas biossalinas. Sendo que a identificação do desempenho germinativo das sementes e do desenvolvimento de plântulas é de fundamental relevância para a reconstituição das áreas degradadas e salinizadas da Caatinga (Dantas et al., 2014).

Entre as principais técnicas para analisar a tolerância das espécies está à avaliação da germinação e do índice de velocidade de germinação de sementes submetidas à salinidade, pois quando estas conseguem estabelecer plântulas normais é um excelente indício de que nos estádios seguintes conseguirão se manter no ambiente (Nogueira et al., 2020).

Assim, mesmo atentando ao fato de que as espécies nativas são adaptadas e que, portanto, conseguiriam desenvolverse bem no ambiente, é necessário um maior aprofundamento em relação à salinidade, pois esta pode impossibilitar a germinação ou o desenvolvimento de plântulas nos casos onde a situação é drástica, a qual dificulta os programas desenvolvidos para a revitalização de algumas áreas (Gonçalves et al., 2020).

Ao verificarem a germinação e o crescimento inicial de plântulas de três espécies florestais nativas da Caatinga, ou seja, canafístula (Peltophorum dubium (Sprengel) Taubert), tamboril (Enterolobium contortisiliquum (Vell.) Morong) e pauformiga (Triplaris americana L.) submetidas ao estresse salino $(\mathrm{NaCl})$, foi verificado que a canafistula e o tamboril reduziram a germinação e o desenvolvimento inicial de plântulas à medida que o nível de salinidade aumentou. Por sua vez, o pauformiga manteve a germinação, índice de velocidade de germinação e a biomassa das plântulas de maneira satisfatória, mesmo com aumento do nível de salinidade (Dutra et al., 2017).

Estudos realizados por Freire et al. (2018), mostraram que a emergência das plântulas de carnaubeira (Copernicia prunifera (Miller) H. E. Moore) foi retardada quando as mesmas foram irrigadas com água salina, obtidas da diluição de cloreto de sódio até a concentração desejada. Além do mais, o índice de velocidade de emergência decresceu com o incremento da salinidade e, as mudas apresentaram efeitos deletérios na área foliar, massa seca da parte aérea, da raiz e total e no índice de qualidade de Dickson; sendo a carnaubeira tolerante até 8,2 dS.m ${ }^{-1}$.

A jurema-branca (Piptadenia stipulacea Benth.) mostrou-se moderadamente tolerante a salinidade, apresentando um bom desenvolvimento a níveis de salinidade de $4,5 \mathrm{dS} . \mathrm{m}^{-1}$, sem que ocorressem perdas significativas na germinação e no número de folhas, mas o aumento da salinidade comprometeu a biomassa das plântulas (Nogueira et al., 2020).

$\mathrm{Na}$ avaliação do efeito de diferentes concentrações salinas, na água de irrigação, sobre a emergência e o crescimento inicial de mudas de pau ferro (Libidibia ferrea (Mart. ex Tul.), foi verificado que o nível salino de 3,4 dS.m ${ }^{-1}$ reduziu a porcentagem de emergência, o índice de velocidade de emergência e o desenvolvimento das plântulas (Bezerra et al., 2020)

A salinidade é um dos problemas de maior impacto nas vegetações nativas da Caatinga, pois esta dificulta a germinação e o desenvolvimento das plântulas das espécies e, além disso, pode gerar plantas frágeis que não possuem uma vida durável (Taiz \& Zeiger, 2010). Ao verificarem as implicações da salinidade sobre a germinação e crescimento inicial de plântulas de jurema-de-embira (Mimosa ophthalmocentra Mart. ex Benth) em diferentes temperaturas, Nogueira et al. (2018) constataram que com o aumento da temperatura, os efeitos da salinidade se intensificaram. Ainda, consideraram a jurema-deembira tolerante, pois manteve uma boa germinação até o nível salino de $16 \mathrm{dS} \cdot \mathrm{m}^{-1} \mathrm{em}$ temperaturas abaixo de $30{ }^{\circ} \mathrm{C}$; sendo que as mudas se desenvolveram até $12 \mathrm{dS} \cdot \mathrm{m}^{-1}$, também em temperaturas inferiores à $30^{\circ} \mathrm{C}$.

Na avaliação de quatro espécies florestais, sendo três nativas da Caatinga, ou seja, aroeira do sertão (Astronium urundeuva Fr. (M. Allemão)), sabiá (Mimosa caesalpiniifolia Benth) e ipê roxo (Tabebuia impetiginosa (Mart. ex. DC.), e uma exótica neem (Azadirachta indica A. Juss) após a submissão à salinidade na fase inicial de crescimento, foi constatado que quando as plantas estão em ambiente salino tendem a reduzir seu crescimento para manter suas atividades vitais e que há redução das atividades fotossintéticas e síntese de proteínas (Lima et al., 2018). 
Além do cloreto de sódio, outros sais que estão presentes tanto no solo como na água para irrigação causam efeitos negativos sobre a germinação e estabelecimento de plântulas. Dentro deste contexto, foi observado que os sais $\mathrm{NaCl}, \mathrm{KCl}$ e o $\mathrm{CaCl}_{2}$ foram prejudiciais ao cedro (Cedrela odorata L.) como declínios da germinação, crescimento do hipocótilo, biomassa e capacidade de estabelecimento de plântulas, à partir de $25 \mathrm{mM}$ e além disso, o $\mathrm{CaCl}_{2} \mathrm{e}$ o $\mathrm{KCl}$ foram mais severos do que o $\mathrm{NaCl}$ (Ferreira et al., 2013). Entretanto, não houve redução da porcentagem de germinação de sementes de acácia (Acacia mangium Willd.), quando as mesmas foram submetidas ao $\mathrm{NaCl}$. Entretanto, houve redução da velocidade do processo germinativo à medida que se elevou o nível de salinidade; por sua vez a partir da concentração de $75 \mathrm{mM}$ de $\mathrm{KCl}$ tanto a germinação como o índice de velocidade de germinação declinaram (Costa et al., 2016).

Analisando os efeitos do $\mathrm{CaCl}_{2}, \mathrm{NaCl}$ e $\mathrm{KCl}$ sobre a germinação e o desenvolvimento de plântulas de mofumbo (Combretum leprosum Mart.) foi observado que o $\mathrm{CaCl}_{2}$ foi mais prejudicial as plântulas do que o $\mathrm{KCl}$ e $\mathrm{NaCl}$, pois ocasionou um menor comprimento da raiz, redução da emergência e baixo desenvolvimento das plântulas; o que destaca que as plantas presentes em um ambiente sofrem impactos negativos baseados no tipo de sal e no grau de tolerância da espécie (Leal et al., 2019).

Quanto à germinação de duas espécies florestais, catingueira (Poincianela pyramidalis (Tul.) L. P. Queiroz) e angico (Anadenanthera colubrina (Vell.) Brenan), ambas com uma vasta distribuição na Caatinga, foi constatado que as mesmas são tolerantes a salinidade, entretanto a catingueira é mais tolerante ao $\mathrm{NaCl}$ do que o angico, e ambas se mostraram sensíveis ao $\mathrm{CaCl}_{2}$, pois a partir do potencial de -0,8Mpa a germinação foi próxima de zero (Santos et al., 2016).

Pesquisas que abordem avaliações do desempenho de mudas de espécies nativas sob estresses diversos, são essenciais para o fornecimento de informações relevantes para o planejamento e desenvolvimento de mudas, direcionadas aos plantios comerciais, revegetação de áreas de extrativismo e preservação ambiental (Guedes et al., 2011).

Com o aumento da importância dos estudos sobre espécies florestais e águas biossalinas, surgiram no decorrer destes, alternativas para que as sementes sofram um menor impacto dos sais ou outros estresses abióticos durante sua germinação (Santos et al., 2020). Destaca-se como uma dessas técnicas o condicionamento fisiológico ou osmótico das sementes, consistindo em embeber a semente em uma solução osmótica ou apenas em água por um determinado período de tempo e temperatura, sem que ocorra a protrusão da raiz primária (Marcos Filho, 2015). A finalidade é de que quando as sementes sejam semeadas, a emergência das plântulas ocorra de forma rápida, uniforme e em maior porcentagem, diminuindo o tempo de exposição das sementes ao ambiente salino (Santos et al., 2020).

Podem ser empregados diferentes agentes osmóticos no condicionamento das sementes entre eles cloreto de sódio $(\mathrm{NaCl})$, nitrato de potássio (KNO), sulfato de magnésio $\left(\mathrm{MgSO}_{4}\right)$, cloreto de magnésio $\left(\mathrm{MgCl}_{2}\right)$, ortofosfato de potássio $\left(\mathrm{KH}_{2} \mathrm{PO}_{4}\right)$, sulfato de manganês $\left(\mathrm{MnSO}_{4}\right)$, manitol e polietilenoglicol (PEG), destacando-se o uso do PEG, já que possui o benefício de não ultrapassar o sistema de membranas e não causar toxidez (Spadeto et al., 2018).

Ao avaliarem as consequências do hidrocondicionamento em sementes de catanduva (Piptadenia moniliformis Benth.), foi constatado que sementes condicionadas foram menos afetadas negativamente pelos sais, além de produzirem plântulas vigorosas e uma porcentagem de germinação até a concentração de -0,9 Mpa (Ramalho et al., 2020).

Cássia-do-nordeste (Cassia excelsa Schrad.), espécie bastante encontrada no nordeste brasileiro com grande potencial para recuperação de áreas degradadas, em condições naturais possui uma baixa taxa de germinação, de maneira que tratamentos pré-germinativos sejam necessários para incrementar o potencial germinativo. Dentro deste contexto, foi avaliado o condicionamento de sementes da referida espécie com PEG 6000 na condição de estresse salino e verificado que o condicionamento foi relativamente eficiente para minimizar os efeitos deletérios do $\mathrm{NaCl}$, possibilitando uma germinação satisfatória nos potenciais de -1,0 a -1,4 Mpa (Jeller \& Peres, 2003). 
O domínio vegetal Caatinga apresenta um grande potencial de desenvolvimento, porém ao longo dos anos essa área vem sendo bastante degradada por ações antrópicas, especialmente, o qual está perdendo grande parte de suas espécies florestais nativas. Por isso é tão importante que nessa região se estabeleça a produção de mudas nativas para a sua recuperação, visto ser um domínio vegetal, exclusivamente brasileiro e muito rico em biodiversidade (Tavares Filho et al., 2020).

A Caatinga está situada em uma região que possui uma baixa disponibilidade de água e ainda é marcada pelo desperdício, como nos casos da irrigação sem planejamento. Em razão da sua formação geológica, as águas situadas no subterrâneo são em sua maioria salinas e salobras (Dantas et al., 2014). Nesta perspectiva, as águas consideradas de má qualidade devem fazer parte do gerenciamento de irrigação, buscando uma adequação para estas.

Contudo, as informações sobre produção de mudas com espécies nativas da Caatinga ainda são insuficientes, necessitando de mais pesquisas para dar suporte à implantação de viveiros florestais, principalmente em condições salinas (Silva et al., 2020).

\section{Considerações Finais}

Na quantificação e qualificação dos artigos científicos com a temática, emprego de águas biossalinas na germinação de sementes de espécies florestais publicados nas bases de dados: Web of Science, Scielo, Periódicos Capes e Google Acadêmico, Acadêmico, a presente revisão de literatura obteve resultados pouco satisfatórios, evidenciando que palavraschave e expressões utilizadas na busca mostraram poucas publicações científicas, cabendo um maior aprofundamento e mais pesquisas para essa temática.

A revisão de literatura ainda evidenciou que as pesquisas que existem voltadas às espécies florestais nativas são de estresses isolados, o que não é encontrado na natureza, sobretudo no domínio vegetal Caatinga. Assim, investigações futuras avaliando a aplicação de fontes simultâneas de estresse são necessárias. Outro fator que deve ser analisado é o limite de tolerância das espécies florestais, assim como também os tipos de sais e sua influência no processo germinativo dessas espécies, uma vez que esses fatores são abordados de maneira pouca especifica nas publicações encontradas.

Nesse cenário, para a reestruturação das áreas degradadas e ambientes salinizados da Caatinga, recomenda-se uma abordagem de forma multidisciplinar nos estudos, envolvendo todas as características presentes neste ambiente e dessa forma as produções científicas irão contribuir com informações relevantes para o desenvolvimento desse domínio vegetal tão rico em biodiversidade.

\section{Referências}

Bezerra, L. T., Santos, A. R. C. D. S., Farias, A. D. S., Souto, P. C., Ferreira, V. M., \& Araújo Neto, J. C. (2020). Emergência e crescimento inicial de plântulas de Libidibia ferrea (Mart. exTul.) em diferentes níveis de salinidade na água de irrigação. Brazilian Journal of Animal and Environmental Research, 3 (3), 1126-1140. doi:10.34188/bjaerv3n3-032

Carvalho, J. S. B., Costa, E. N., Pamplona, A. L Q., Chagas, C. T. G. D., Sariava, M. P., Rodrigues, A. E., Pamplona., \& Quadros, B. R. D. (2020). Estresse salino por $\mathrm{NaCl}$ em sementes de Paineira e Pau de Balsa. Brazilian Journal of Development, 6 (6), 42134-42146. doi:10.34117/bjdv6n6-667

Carvalho, L. L. S de, Lacerda, C. F., Lopes, F. B., \& Gomes Filho, R. R. (2020). Variabilidade espaç o-temporal da qualidade das águas subterrâneas em área irrigada no semiárido brasileiro. Research, Society and Development, 2507(1), 1-9. doi:10.33448/rsd-v9i8.5786

COSTA, E. N., Carvalho, J. S. B., Pamplona, A. L. Q., Chagas, C. T. G., \& Quadros, B. R. (2016). Sementes de acácia mangium wild submetidas a estresse salino. Revista Cultivando o Saber, 152 (3), 73-84.

Dantas, B. F., Ribeiro, R. C., Oliveira, G. M., Silva, F. F. S., \& De Araújo, G. G. L. (2019). Biosaline production of seedlings of native species from the caatinga dry forest. Ciencia Florestal, 29 (4), 1551-1567. doi:10.5902/1980509831221

Dantas, B. F., Ribeiro, R. C., Matias, J. R., \& Araújo, G. G. L. (2014). Metabolismo Germinativo De Espécies Florestais Da Caatinga Em Agricultura Biossalina. Journal of Seed Science, 36(2), 194-203. doi:10.1590/2317-1545v32n2927

Dutra, T. R., Massad, M. D., Moreira, P. R., \& Ribeiro, É. S. M. (2017). Efeito da salinidade na germinação e crescimento inicial de plântulas de três espécies arbóreas florestais. Pesquisa Florestal Brasileira, 37 (91) 323-330. 
Ferreira, E. G. B. S., Matos, V. P., Sena, L. H. M., Oliveira, R. G., \& Sales, A. G. A. (2013). Processo germinativo e vigor de sementes de Cedrela odorata L. sob estresse salino. Ciencia Florestal, 23 (1), 99-105.

Freire, J. O., Santos, N. A., Arruda, J. A., Cruz, T. M. L., Nascimento, G. S. (2018). Qualidade de mudas de carnaubeira (Copernicia prunifera - Miller - H. E. Moore) irrigadas com águas salinas. Brazilian Journal of Animal and Environmental Research, 4 (1), 295-309.

Gonçalves, M. P. M., Feliciano, A. L. P., Silva, A. P., Silva, L. B., Silva, K. M., Silva Júnior, F. S., Grugiki, M. A., \& Silva, M. I. O. (2020). Influência de diferentes tipos de solos da Caatinga na germinação de espécies nativas. Brazilian Journal of Development, 6(1), 1216-1226. doi:10.34117/bjdv6n1-085

Guedes, R. S., Alves, E. U., Galindo, E. A., \& Barrozo, L. M. (2011). Estresse salino e temperaturas na germinação e vigor de sementes de Chorisia glaziovii O. kuntze. Revista Brasileira de Sementes, 33 (2), 279-288.

Jeller, H, Perez, S. C. J. G. A. (2003). Efeitos dos estresses hidrico e salino e da ação de giberelina em sementes de Senna spectabilis. . Ciência Florestal, 38 (9)1, 1025-1034. doi:10.1590/s0100-204x2003000900002

Leal, C. C. P., Dantas, N. B. L., Torres, S. B., Vale, A. A. M., \& Freitas, R. M. O. (2019). Initial development of Combretum leprosum Mart. seedlings irrigated with saline water of different cationic natures. Revista Ciência Agronômica, 50 (2), 300-306. https://doi.org/10.5935/1806-6690.20190035

Lima, A. T., Cunha, P. H. de J., Dantas, B. F., \& Meiado, M. V. (2018). Does discontinuous hydration of senna spectabilis (DC.) H.S. Irwin \& Barneby var. excelsa (Schrad.) H.S. Irwin \& Barneby (Fabaceae) seeds confer tolerance to water stress during seed germination? Journal of Seed Science, 40 (1), 36-43. doi:10.1590/2317-1545v40n1182838

Lima, A. T., Oliveira, B. A., \& Meiado, M. V. (2020). Gibberellic acid provides greater tolerance to saline stress in cactus seed germination. Communications in Plant Sciences, 10 (2020), 80-84. https://doi.org/10.26814/cps2020011

Marcos Filho, J. (2015). Fisiologia de sementes de plantas cultivadas. ABRATES, 659 p.

Martins, G. A., PINTO, R. L. (2001). Manual para elaboração de trabalhos acadêmicos. Atlas.

Nogueira, N. W., Torres, S. B., Freitas, R. M. O., Santos, P. C. S., Sá, F. V. S., \& Leite, M. D. (2018). Salt stress and temperatures on the germination and initial growth of 'jurema-de-embira' (Mimosa ophthalmocentra) seedlings. Revista Brasileira de Engenharia Agricola e Ambiental, 22 (4), $273-278$. doi:10.1590/1807-1929/agriambi.v22n4p273-278

Nogueira, N. W., Freitas, R. M. O., Leal, C. C. P., \& Torres, S. B. (2020). Estresse salino na emergência e desenvolvimento inicial de plântulas de juremabranca. Advances in Forestry Science, 7 (3), 1081-1087. doi:10.34062/afs.v7i3.8624

Nogueira, N. W., Lima, J. S. S., Magno, R. O., Ribeiro, M. C. C., Leal, C. C. P., \& Pinto, J. R. S. (2012). Efeito da salinidade na emergência e crescimento inicial de plântulas de flamboyant. Revista Brasileira De Sementes, 34 (3), 466-472.

Ramalho, L. B., Benedito, C. P., Pereira, K. T. O., Silva, L, C. N., \& Medeiros, H. L. S. (2020). Hidrocondicionamento de sementes de Piptadenia moniliformis Benth. e seus efeitos sobre a tolerância ao estresse salino. Ciência Florestal, 30 (1), 221-230. doi:10.5902/1980509829998

Ramos, D. L. D., Santos, R. S., Matias, J. R., Reis, R. C. R., \& Dantas, B. F. (2018). Processo germinativo e teor de proteínas de aroeira-do-sertão (Astronium urundeuva Fr. (M. Allemão).) germinadas em água biossalina. Journal of Materials Processing Technology, 1(1), 1-8.

Santos, P. R., Vasconcelos, G. S., Lima, B. L. C., Oliveira, D. A. S., Felinto, A. C., Santos, C. G. (2013). ONG na produção de mudas no semiárido de Pernambuco: uma busca pela recuperação ambiental. Journal of Chemical Information and Modeling, 53 (9), 1689-1699.

Santos, A. S., Lopes, K. P., Rodrigues, M. H. B. S., Limão, M. A. R., \& Barbosa, L. S. (2020). Potencial da técnica do osmocondicionamento de sementes como estratégia para minimizar os efeitos da salinidade. Meio Ambiente, 2 (2), 56-61.

Santos, C. A., Silva, N. V., Walter, L. S., Silva, E. C. A., \& Nogueira, R. J. M. C. (2016). Germinação de duas espécies da caatinga sob déficit hídrico e salinidade. Pesquisa Florestal Brasileira, 36 (87), 219. doi:10.4336/2016.pfb.36.87.1017

Silva, D. G. V., \& Trentini, M. (2002). Narrativas como técnica de pesquisa em enfermagem. Rev. Latino-Am. de Enferm.

Silva, N. L. F., Silva, F. L., Lima, A. S., Santos, E. C. X. R., Diniz, J. P. C., \& Santos, J. G. R. (2020). Produção orgânica de mudas de essências florestais nativas e distribuição em comunidades rurais do semiárido paraibano. Caderno Verde de Agroecologia e Desenvolvimento Sustentável, 9 (7), 7040. doi:10.18378/cvads.v9i7.7040

Spadeto, C., Hilda, L., Mengarda, G., Cristina, M., Carlos, J., Miele, L., \& Matheus, T. (2018). Embebição, osmocondicionamento e viabilidade de sementes de apuleia leiocarpa (VOGEL.) J. F. Macbr. Ciência Florestal, 28 (1), 80-89.

Taiz, L., \& Zeiger, E. (2010). Fisiologia vegetal.(5a. ed). Artmed, 918.

Taiz, L., Zeiger, E., Moller, I. max, \& Murphy, A. (2017). Fisiologia e desenvolvimento vegetal. Diversidade vegetal. In Artmed.

Tavares Filho, G. S., Silva, D. F., Lins, R. C., Araújo, C. A. S., Oliveira, F. F., \& Matias, S. S. R. (2020). Desenvolvimento de mudas de Moringa oleífera (LAM) submetida a diferentes níveis de água salina. Brazilian Journal of Development, 6(7), 48671-48683.

Trentini, M., Paim, L. (1999). Pesquisa em Enfermagem. Uma modalidade convergente-assistencial. Editora da UFSC. 